\title{
Parque Nacional da Chapada das Mesas (Maranhão/Brasil): atividades socioeconômicas dos moradores e seus reflexos
}

A pesquisa descreve as atividades socioeconômicas dos moradores que residem dentro e no entorno do Parque Nacional da Chapada das Mesas, estado do Maranhão, bem como as práticas de manejo para a exploração dos recursos naturais. Dessa forma, realizou-se pesquisa descritiva com abordagem quantiqualitativa. Os dados foram levantados no segundo semestre de 2016 com aplicação de formulários em 40 dos 130 domicílios reconhecidos pelo Instituto Chico Mendes de Conservação da Biodiversidade. Observou-se que a agricultura de subsistência se destacou com o cultivo do Phaseolus vulgaris, Oryza sativa, Manihot essculenta e Zea mays. Na prática do extrativismo, Mauritia flexuosa, Platonia insignis, Caryocar brasiliense e Orbignya speciose são os produtos mais coletados; na criação de animais, Gallus gallus domesticus e Bos taurus. Percebeu-se que a agricultura de subsistência e a criação de animais bovinos são as atividades econômicas que mais perturbam ao ambiente devido a forma de manejo. Entretanto, constatou-se que após a criação do Parque Nacional, as comunidades despertaram para o uso de práticas sustentáveis para exploração dos recursos naturais.

Palavras-chave: Comunidades tradicionais; Consciência ecológica; Recursos naturais; Sustentabilidade.

\section{Chapada das Mesas National Park (Maranhão/Brazil): socio- economic activities of dwellers and their reflexes}

\begin{abstract}
The research describes the socioeconomic activities of dwellers living in and around the Chapada das Mesas National Park, State of Maranhão, as well as management practices for the exploitation of natural resources. Thus, a descriptive research with quantitative and qualitative approach was performed. The data were collected in the second half of 2016 with application forms in $\mathbf{4 0}$ of the 130 households recognized by the Instituto Chico Mendes de Conservação da Biodiversidade. Subsistence agriculture stood out with the cultivation of Phaseolus vulgaris, Oryza sativa, Manihot esculenta and Zea mays. In the practice of extractivism, Mauritia flexuosa, Platonia insignis, Caryocar brasiliense and Orbignya speciose. Are the most collected products; In livestock breeding, Gallus gallus domesticus and Bos taurus. It was noticed that subsistence agriculture and cattle breeding are the economic activities that most disturb the environment due to management. However, it was found that after the creation of the National Park, communities awoke to the use of sustainable practices for the exploitation of natural resources.
\end{abstract}

Keywords: Traditional communities; Ecological awareness; Natural resources; Sustainability.

\section{Topic: Uso de Recursos Naturais}

Reviewed anonymously in the process of blind peer.
Received: 09/02/2020

Approved: 09/03/2020
Maria Lindalva Alves da Silva (iD)

Universidade Estadual do Maranhão, Brasil http://lattes.cnpq.br/3004179759769388 http://orcid.org/0000-0002-1555-1521

lindalva.maria@hotmail.com

Maria de Fátima Veras Araújo

Universidade Estadual do Piauí, Brasil

http://lattes.cnpq.br/5210437800253488

http://orcid.org/0000-0002-1653-8476

maria.fveras2018@gmail.com

Gonçalo Mendes da Conceição (ic

Universidade Estadual do Maranhão, Brasil

http://lattes.cnpq.br/0605946383963749

http://orcid.org/0000-0001-9056-9070

doutorgoncalo@gmail.com
Referencing this:

SILVA, M. L. A.; ARAÚJO, M. F. V.; CONCEIÇ̃̃O, G. M.. Parque Nacional da Chapada das Mesas (Maranhão/Brasil): atividades socioeconômicas dos moradores e seus reflexos. Revista lbero Americana de Ciências Ambientais, v.11, n.2, p.381-392, 2020. DOI:

http://doi.org/10.6008/CBPC2179-6858.2020.002.0035 


\section{INTRODUÇÃO}

Nas paisagens do sertão nordestino encontra-se a figura do 'sertanejo' que retira da floresta os recursos naturais necessários para sua sobrevivência e que compartilham, portanto, suas experiências aos demais membros familiares, responsáveis por manter a continuidade das tradições culturais (MARQUES, 2012). A cerca dos saberes dos povos e comunidades tradicionais, Barreto Filho (2006) relata que:

No Brasil foi influenciada por alguns vetores, que nem sempre homogêneos ou concordantes entre si: 1) pela influência das discussões no âmbito internacional sob o crivo das áreas protegidas; 2 ) por essas mesmas discussões internacionais a respeito de pessoas e APs, mas segundo seu desenvolvimento no âmbito nacional; 3) pelas mobilizações locais, cujos grupos sociais portadores de identidade étnica e coletiva passaram a incorporar a variável ambiental como dimensão de suas lutas políticas por direito a terras e acesso aos recursos naturais, que resultou na política de reconhecimento dos povos das comunidades tradicionais.

Nesta perspectiva, geralmente, as famílias que ocupam esses territórios têm como meio de sobrevivência a prática da agricultura familiar e a criação de animais. Desta forma, Silva et al. (2018) inferem:

A criação de unidades de conservação se tornou um meio de fomentar o crescimento de países como o Brasil, dono de uma diversidade biológica, como confere sua paisagem de país tropical, que tem conseguido agregar ao turismo ecológico valores econômicos e chamar atenção de seus visitantes para as questões ambientais e a importância da conservação.

Estes espaços territoriais também são utilizados para implantação de áreas protegidas, em cumprimento à Lei Federal no 9.985/2000, que instituiu o Sistema Nacional de Unidades de Conservação (SNUC), geralmente criadas em terras particulares (BRASIL, 2000). De acordo com Campos et al. (2016), as unidades de conservação (UCS) têm "o propósito de promover a conservação do ambiente a partir da manutenção dessas áreas e da implementação de ações sustentáveis, face aos críticos níveis de degradação ambiental, em que se encontram esses santuários ecológicos".

Guanaes (2006) afirma que por trás do processo de criação de áreas protegidas, são geradas expectativas por parte de todos os atores sociais envolvidos, com destaque para os que residem nas áreas de amortecimento e no seu interior, pois a territorialidade antes vista de maneira subjetiva, agora sofre transformação no jeito de ver e agir das pessoas.

Diegues (1996) e Costa (2013) comentam que tais comunidades não utilizam práticas produtivas incompatíveis com as diretrizes do SNUC, ao se referirem a populações tradicionais, tendo em vista, sua dependência do mundo natural, através da forma de produção e de viver, pois alguns deles vivem em regiões próximas a riachos, igarapés, rios, entre outros atributos naturais.

Castilho et al. (2009), Collins (2010) e Bruno et al. (2018) argumentam que os povos das comunidades tradicionais são grupos sociais que conseguem manter um mútuo relacionamento entre a percepção, manutenção de suas necessidades básicas, sentimento de pertencimento e estabilidade do lugar onde vivem com suas tradições culturais e o respeito ao meio ambiente, garantindo assim, a conservação dos recursos naturais e manutenção da biodiversidade

Para Figueiredo (2011), quando se cogita a restrição do uso dos recursos naturais em unidades de conservação por populações que residem entorno destas áreas, recomenda-se a reflexão sobre a sociedade 
e a natureza, pois, determinadas atitudes podem acelerar os conflitos entre estes atores sociais e a gestão pública destas áreas de preservação. Conforme Shiraishi (2010) no Brasil, o conflito em torno da criação de unidades de conservação se torna corriqueiro e se agrava ainda mais através de questões de natureza sociais, como saúde, alimentação, moradia, entre outras políticas públicas sociais ausentes em regiões rurais brasileiras.

Com base nos argumentos supracitados, o artigo descreve as atividades socioeconômicas dos moradores que residem no interior e ao entorno do Parque Nacional da Chapada das Mesas (MA), bem como as práticas de manejo para a exploração dos recursos naturais.

A justificativa da pesquisa baseia nas discussões sobre a permanência de seres humanos em áreas de conservação de Proteção Integral, pois, de acordo com o SNUC, nestas áreas são permitidas apenas atividades voltadas para o turismo, atividades pedagógicas e pesquisas de cunho científico.

\section{MATERIAIS E MÉTODOS}

\section{Área de Estudo}

O Parque Nacional da Chapada das Mesas (PNCM) possui uma área de 160.046 ha, abrange os municípios de Carolina, Riachão e Estreito, no estado do Maranhão. O objetivo de sua criação foi a preservação de ecossistemas naturais de grande relevância ecológica e beleza cênica locais, a realização de pesquisas científicas, e o desenvolvimento de atividades de educação ambiental e turismo ecológico (ICMBio et al., 2016a).

Neste contexto, os habitantes das comunidades tradicionais que residem no interior e entorno da Unidade de Conservação contam com uma diversidade de recursos naturais que ajudam na produção de alimentos através da prática da agricultura familiar, do extrativismo vegetal e da criação de animais com destaque para a criação de gado bovino (Figura 1).

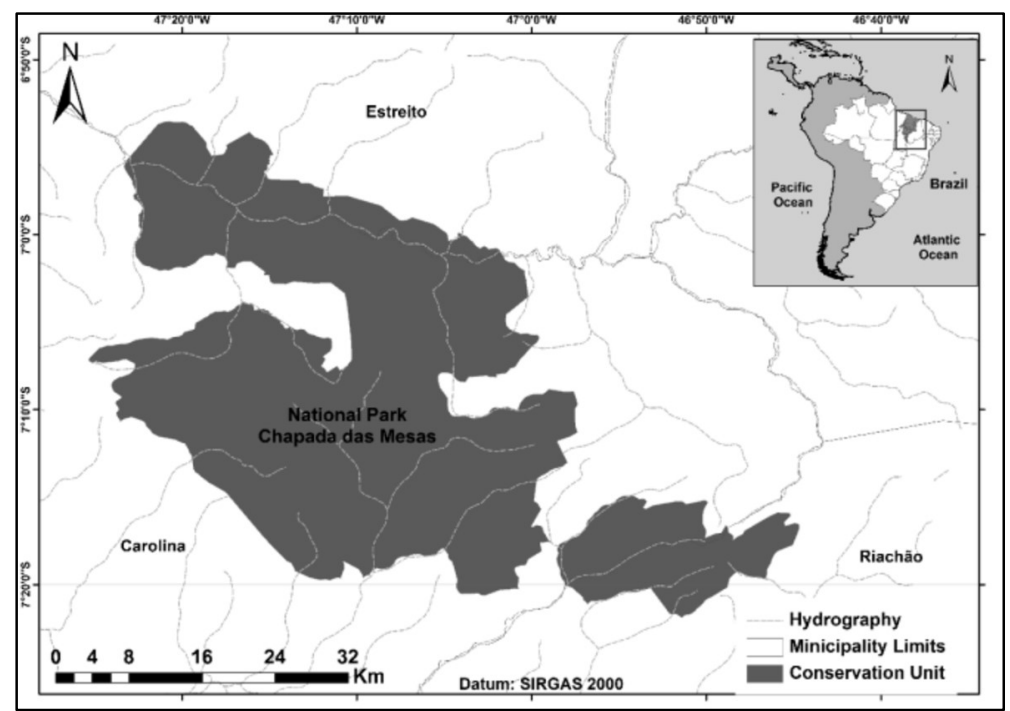

Figura 1: Mapa de localização do Parque Nacional da Chapada das Mesas/MA. Fonte: ICMBio et al. (2016b).

A UC se localiza sob as coordenadas 70 19' $0^{\prime \prime}$ de latitude Sul e 47 $20^{\prime}$ 06" de longitude Oeste (Figura 1). O mapa da Figura 2 mostra a localização das comunidades tradicionais que serviram de objeto desta 
pesquisa.

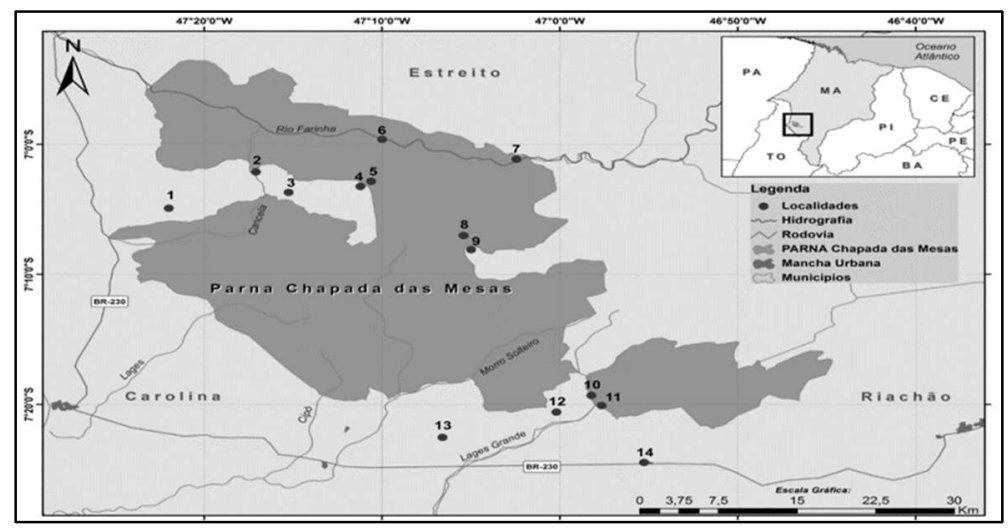

Figura 2: Mapa de localização das comunidades tradicionais visitadas no Parque Nacional da Chapada das Mesas/MA. Fonte: MMA (2015). Organização: SILVA (2016). Comunidades: 1. Santo Antonio 2. Faz. Tapuio 3. São Bráz 4. Anita

Pires 5. Faz. Jurema 6. Cachoeira da Prata 7. Cachoeira do São Romão 8. Canto do Balaio 9. Canto do Porto 10. Canto do Remanso 11. Mutum 12. Solta 13. São José dos Pereiras 14. Alto Bonito.

\section{Procedimento metodológico}

A pesquisa foi de cunho descritivo, com abordagem quanti-qualitativa, com base em especificidades a definição de uma determinada população, pois, Gil (2011) afirma que, "são inúmeros os estudos que podem ser classificados sob este título e uma de suas características mais significativas está na utilização de técnicas padronizadas de coletas de dados".

Com base nos estudos de Lakatos et al. (2011), o estudo visou obter informações sobre atividades socioeconômicas de sobrevivência das comunidades tradicionais do interior e entorno do Parque Nacional da Chapada das Mesas, além da análise qualitativa dos valores, das compreensões e interpretações dos moradores pesquisados.

A técnica de coleta de dados aplicada foi a observação indireta e aplicação de formulário semiestruturado em 40 dos 130 domicílios localizado na área de abrangência da UC, de acordo com a Nota Técnica no 001/2016 do Instituto Chico Mendes da Conservação da Biodiversidade, no segundo semestre de 2016 (ICMBio et al., 2016b).

Quanto à elaboração do formulário, optou-se por questões fechadas e abertas do tipo dicotômicas. As questões dicotômicas, como ressalta Mattar (2007), têm a rapidez na coleta das respostas e agilidade na tabulação dos dados para análises posteriores.

Para aplicação do formulário junto aos residentes, foi necessário submeter à pesquisa ao Comitê de Ética e Pesquisa do Centro de Estudos Superiores de Caxias/Certificado de Apresentação para Apreciação Ética (CEP/CAAE), sendo aprovada com o número de protocolo 57683316.5.000.554; ao Instituto Chico Mendes da Conservação da Biodiversidade/Sistema de Autorização de Material Biológico (ICMBio/SISBIO), com protocolo número 54126-1, autorizando os moradores a responder o formulário; e assinatura do Termo de Consentimento Livre e Esclarecido (TCLE) pelos participantes da pesquisa.

\section{RESULTADOS E DISCUSSÃO}


Através do formulário aplicado, verificou-se que os produtos agrícolas mais cultivados pelos moradores do entorno e interior do PNCM, conforme foi observado na Figura 3, foram: feijão (Phaseolus vulgaris L.), arroz (Oryza sativa L.), mandioca (Manihot esculenta Crantz), milho (Zea mays L.); seguidos pelas hortaliças, como alface (Lactuca sativa L.), coentro (Coriandrum sativum L.) e cebolinha (Allium fistulosum L.). No grupo das frutíferas, destacam-se a banana (Musa paradisíaca L.), melância (Citrullus vulgaris Scharad), manga (Mangifera indica L.), cana-de-açúcar (Saccharum officinarum L.) e melão (Cucumis melo L.).

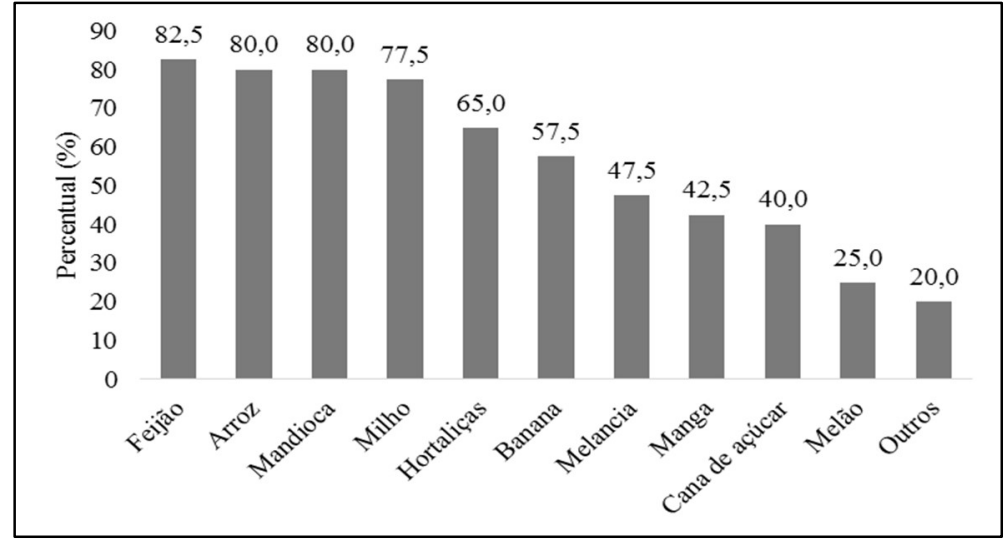

Figura 3: Principais produtos agrícolas cultivados pelos moradores.

As famílias sobrevivem da agricultura de subsistência e representam agricultores familiares, utiliza o fogo no preparo das roças, o que pode causar impacto negativo ao solo e à vegetação. Ferreira et al. (2015) ressaltam que a colonização do território brasileiro tem sido marcada, historicamente, pela exploração da paisagem culminando com o desaparecimento da vegetação nativa, com intensa atividade antrópica, com destaque para a prática da agricultura, criação de animais e exploração da madeira.

Apesar de muitos ambientalistas entenderem que a prática do roçado para plantio das culturas de arroz, feijão, milho e mandioca, como principais produtos agrícolas cultivados em regiões rurais, têm causado impactos negativos na área de preservação, percebeu-se que a expansão do agronegócio na região de amortecimento da UC tem se intensificado e acelerado o processo de desmatamento naquela região, provocando danos ambientais como a perda da biodiversidade em maiores proporções do que as atividades socioeconômicas dos moradores.

Neste contexto, Silva et al. (2017) compreendem que "as comunidades tradicionais são grupos de pessoas que mantém a tradição cultural, através de seus costumes, crenças e valores, bem como exploram os recursos naturais para sua sobrevivência preocupando-se com as gerações futuras". Nas palavras dos autores, entende-se que a prática da agricultura de subsistência não traz grande impacto ambiental na região do PNCM, pois ainda utilizam técnicas rudimentares para as pequenas áreas plantadas.

Além dos cultivos mencionados, as famílias têm em seus quintais canteiros com algumas espécies de hortaliças, como a cebolinha, coentro, pimentão, tomate, dentre outras, utilizando adubos orgânicos, sem o uso de produtos químicos. Também são encontradas algumas espécies frutíferas, como a banana, melancia e melão utilizado para consumo próprio ou comercializado em pequena escala. Para Diegues (1996), as comunidades tradicionais participam das transformações sociais com o consumo de produtos 
industrializados em ritmo mais lento e a forma de manejo do solo para a prática da agricultura colabora na conservação destas áreas.

De acordo com o Decreto Federal no 6.040/2007, que instituiu a Política Nacional de Desenvolvimento Sustentável dos Povos e Comunidades Tradicionais (BRASIL, 2007), os moradores praticam a agricultura de subsistência para manter as necessidades básicas de seu grupo familiar. A prática da agricultura de subsistência é uma característica de comunidades rurais, em assentamentos e comunidades tradicionais, como foi relatado nos estudos de Pinto et al. (2006), em comunidades rurais da Mata Atlântica na Bahia sobre conhecimentos de plantas medicinais, caso semelhante descrito por Carvalho et al. (2013), em comunidades de Várzea Grande e Garanhuns em Pernambuco.

Também, buscou-se investigar algumas informações sobre a atividade agrícola, como, por exemplo, se recebem ou não assistência técnica de programas de assistência ao agricultor familiar, se usa produtos químicos na plantação destes cultivares. De acordo com os entrevistados, $90 \%$ dos moradores informaram que não recebem apoio do Programa de Apoio à Assistência Técnica da Agricultura Familiar, 7,5\% não responderam e 2,5\% disseram que já foram comtemplados. Entretanto, $80 \%$ não souberam responder se consideram ou não importante o apoio técnico ou financeiro do Programa Agricultura Familiar, 3\% não consideram importante o apoio técnico de profissionais e aos programas e 12,5\% entenderam que esse apoio técnico é necessário.

De acordo com Olaide et al. (2004), o programa tem como premissa a diversificação da cadeia produtiva e a durabilidade dos recursos naturais com ênfase na qualidade de vida do cidadão. De acordo com as considerações do autor, entende-se que a implantação desse programa é uma forma sustentável de desenvolvimento econômico, para que o pequeno produtor tenha acesso a técnicas de manejo sustentável na produção agrícola.

Neste contexto, as famílias da região da Chapada das Mesas não recebem apoio técnico para desenvolver estratégias de manejo sustentável e, por conseguinte, não sabem da importância do programa para suas atividades agrícolas.

Em relação apoio técnico e financeiro do Programa de Agricultura Familiar, apenas um morador de uma comunidade que faz parte do município de Carolina, afirmou ter recebido para implantação de uma horta. Através de conversas informais, alguns moradores relataram que foram adquiridos recursos financeiros para aquisição de bens materiais, como bomba, ferramentas, construção da casa do gerador, entre outros, além de mudas e sementes para plantio.

Considerando o uso de defensivos agrícolas, $85 \%$ dos moradores afirmaram que não utilizam produtos químicos nas plantações e $15 \%$ já fizeram uso de algum destes produtos. Quanto ao uso de fertilizantes, $85 \%$ não utilizam, 3\% declararam que usaram e 3\% não responderam. Os moradores alegam a boa qualidade do solo para o não uso de produtos químicos nas roças. Conforme relatos de alguns moradores que participaram da pesquisa, o solo que forma a região de chapada possui características físico-químicas e biológicas consideradas de boa qualidade, não necessitando, portanto, de uso de defensivos agrícolas.

O extrativismo vegetal é uma prática comum em comunidades tradicionais e na região da chapada é 
um complemento da renda das famílias. Indagados sobre a atividade, $70 \%$ dos pesquisados disseram que usam a coleta de frutos nativos e $30 \%$ não realizam essas atividades como complemento da renda familiar. Entre os principais frutos nativos mais coletados estão o buriti (Mauritia flexuosa L.f.), bacuri (Platoniain signis Mart.), pequi (Caryocar brasiliense Cambess), coco babaçu (Orbignya speciosa Mart.), conforme a Figura 4.

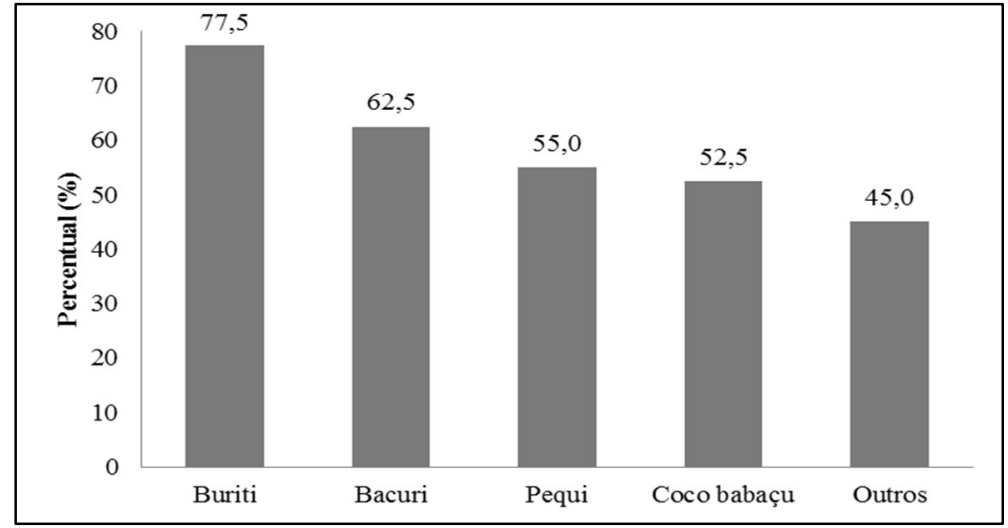

Figura 4: Frutos nativos coletados no extrativismo.

Os moradores têm no extrativismo outra atividade econômica. Essa prática é considerada uma atividade sustentável. Nesta perspectiva, o Brasil como detentor de uma grande parte de biodiversidade do planeta, possui uma riqueza de espécies nativas que garantem a renda de centenas dos povos que vivem em região de floresta, como ribeirinhos, caiçaras, indígenas, quilombolas, no caso da região Nordeste, os sertanejos (MARQUES, 2012).

Os frutos nativos também são utilizados na alimentação diária, bem como na comercialização e abastecimento do mercado interno e de outros estados como Piauí e Ceará. Portanto, a prática do extrativismo para as comunidades é uma forma de retirar da natureza os recursos naturais para sua sobrevivência e ao mesmo tempo de mantê-los preservados.

Além da coleta dos frutos frescos, $30 \%$ das famílias comercializam os subprodutos derivados, $42,5 \%$ não realizam essa prática e $27,5 \%$ não responderam. Quanto ao beneficiamento dos frutos nativos na produção de derivados, os subprodutos mais produzidos são doces e polpas usados na comercialização e consumo. $\mathrm{O}$ extrativismo é uma cultura que deve ser preservada pelas comunidades e para Toledo et al. (2009):

Todo produtor rural necessita dispor de 'meios intelectuais', ou seja, de conhecimentos sobre seu entorno para realizar a apropriação de suas naturezas. Esses conhecimentos têm um valor substancial para clarificar as formas como as populações tradicionais percebem, concebem e conceituam os recursos, paisagens ou ecossistemas sobre os quais centram seus processos de reprodução sociocultural. Mais ainda, no contexto de uma economia de subsistência, esse conhecimento sobre a natureza se converte em um componente decisivo para o esboço e implantação de estratégias de sobrevivência.

A preferência pelo doce, se deve ao fato de a matéria-prima ser o buriti e não necessitar de acondicionamento em freezer ou geladeira. São utilizados a palha e o caule do buriti na confecção de caixas, as quais servem de recipientes para armazenar o doce, comercializado nas feiras e mercados municipais locais. As polpas, óleos comestíveis, sucos e o fruto seco são usados para consumo próprio e vendidos aos turistas que visitam as atrações turísticas do Parque. 
Os moradores que fazem parte do município de Riachão informaram que a base da economia é a coleta dos frutos nativos, pois, segundo eles, o solo não é bom para plantação de culturas de arroz, milho, feijão e mandioca, como nas demais comunidades investigadas.

As comunidades utilizam não só o fruto nativo na alimentação e comercialização para ajudar no sustento das famílias, mas também fazem uso de outras partes desses vegetais. Em estudo realizado por Marques (2012), na região da chapada que faz parte do município de Carolina/MA, as famílias usam o caule do bacuri para cobertura de teto de casas conhecido como "cavaco", além de utensílios domésticos, como o pilão, feito do caule do pequi; as folhas do buriti e do babaçu são usadas na construção de moradias e confecção de artesanato comercializado em Carolina.

A partir da criação da Unidade de Conservação em 2005 (BRASIL, 2005), nessa região, o uso dos recursos naturais tornou-se limitados pelos moradores, assim, 77,5\% afirmaram que já fizeram a extração da madeira, $20 \%$ informaram que não e $2,5 \%$ não responderam. Esses dados demonstraram os impactos ambientais com o desmatamento da área utilizada para vários fins, como, a comercialização da madeira, uso na agricultura e pastagem para o gado bovino.

Estudos realizado por Silva et al. (2016) que reportava a percepção dos moradores quanto aos problemas ambientais na área de abrangência do PNCM, as mulheres apontaram o desmatamento e os homens, as queimadas. Neste sentido, a implantação da UC foi uma estratégia preservacionista encontrada para conter os avanços de retirada da mata nativa nesta região considerada um ecótono importante para manutenção da biodiversidade do Cerrado local.

O desmatamento é um dos problemas socioambientais do país, pois, trata-se de um comércio que movimenta milhões de reais, fomentados por empresários da indústria madeireira, que se instalam clandestinamente nas florestas brasileiras para derrubada da vegetação nativa. A aprovação da Lei Federal no 9.605/98 foi uma forma que o governo encontrou para coibir vários crimes ambientais, dentre eles, o desmatamento (BRASIL, 1998).

Outro fator que contribuiu para minimizar os impactos ambientais causados pelo desmatamento foi a realização de Conferências Internacionais sobre o Meio Ambiente, cujo objetivo, no primeiro momento, estava em rever o sistema de produção dos países desenvolvidos, e posteriormente, despertar a compreensão de que o subdesenvolvimento é a principal razão da questão ambiental na percepção de Lago (2006) ao inferir sobre os fatores que contribuem para as mudanças climáticas no planeta.

Essas providências fazem parte de acordos assinados como metas pré-estabelecidas não apenas pelo Brasil, mas por vários países, com o compromisso de desenfrear o desmatamento. Neste contexto, a criação das unidades de conservação surgiu como política de preservação de áreas consideradas ricas em patrimônio ecológico em todo o planeta e como apelo dos ambientalistas preocupados com a manutenção da biodiversidade.

Na visão de Mota et al. (2009), essa preocupação é provocada pelo aumento da devastação, em todo o mundo, de muitas áreas de floresta. De acordo Godard et al. (2002), as questões ambientais são frutos da intensa produção e consumismo desenfreado das pessoas. 
A domesticação de animais em pequena escala de forma extensiva como destaque para bovinos, caprinos e ovinos é uma atividade econômica que caracteriza uma população tradicional, sendo, portanto, uma atividade muito comum nas regiões do Nordeste brasileiro. De acordo com a Figura 6, verificou-se que 97,5\% dos moradores criam galinhas (Gallus gallus domesticus L.); bovinos (Bos taurus L.); suinos (Sus domesticus L.); capotes (N. meleagris L.); patos (Cairina moschata L.); caprinos (Capra aegragrus hircus L.) e ovinos (Ovis aries L.).

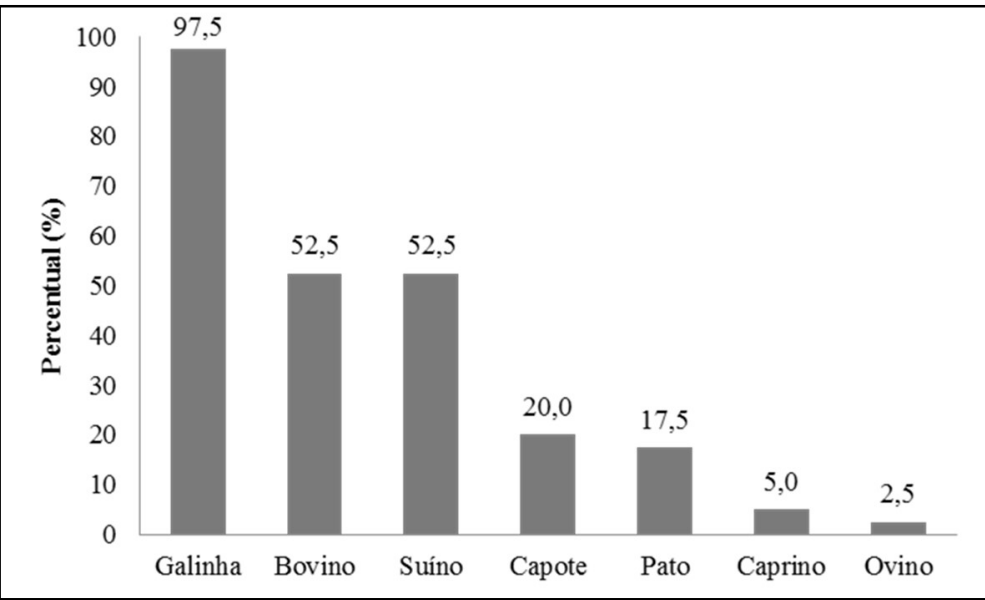

Figura 5: Rebanhos criados pelos moradores das comunidades tradicionais

A criação de animais é uma atividade econômica tradicional, seguida ao longo do tempo pelas comunidades rurais para suprir a base alimentar e como meio de renda no sustento de suas famílias. Nas comunidades inseridas em áreas do entorno e no interior do Parque, cria-se galinha nos quintais de suas residências, como alimento, que compõe com o arroz e o feijão o prato típico da comida local, além de fazer parte de um dos pratos dos restaurantes instalados em locais das atrações turísticas muito visitadas pelos turistas: as cachoeiras do São Romão e da Prata, atributos naturais que ficam no interior da área de proteção, bem como dos balneários situados no entorno.

Segundo Wüst et al. (2015), a criação de gado bovino pode causar a degradação no solo e a perda da biodiversidade. Na ótica de Araújo et al. (2010), a criação de gado causa prejuízos ambientais e ecológicos. A criação de gado por parte dos moradores é uma atividade que compromete a manutenção da biodiversidade, uma vez que o pisoteio do gado, a eliminação de gás metano pelas fezes do animal e a utilização do fogo para pastagem, são ações antrópicas que contribuem com grandes impactos ao ambiente.

De acordo com informações do gestor do Parque Nacional, os criadores de gado são orientados para o uso do controle do fogo para pastagem do animal, após a implantação da UC nesta região, o que tem contribuído para conservação das áreas naturais do Parque em estudo. Os moradores criam animais bovinos e utilizam grandes áreas de suas propriedades, alguns deles levam o gado para o topo das serras, colaborando para que essa parte do Parque Nacional sofra grande impacto pelos produtos tóxicos liberados no ambiente (MARQUES, 2012).

A criação de abelhas para extração do mel através de uma associação de produtores de mel no povoado Solta, comunidade de amortecimento do Parque, a qual faz parte do município de Carolina e o 
fomento ao turismo ecológico são consideradas práticas sustentáveis recentes que estão sendo viabilizadas após a implantação da UC na região de acordo com Silva et al. (2018).

$\mathrm{Na}$ comunidade Solta, as famílias estão organizadas em associação com sede própria, no beneficiamento dos produtos derivados do mel, os quais são comercializados para outras regiões circunvizinhas. Henry-Silva (2005) relatou na Conferência das Nações Unidas sobre Meio Ambiente e Desenvolvimento-ECO 92, no art. 6ำ, na Convenção da Biodiversidade, que é preciso traçar programas e planos para utilização sustentável da diversidade biológica.

Com a criação da área de preservação na região da Chapada das Mesas, foi instalado um programa de combate ao incêndio de origem natural ou antrópico intitulado Monitoramento de Incêndio Florestal (MIF), implantado em 2016, o qual consiste no plano de prevenção e combate a incêndios florestais para atuação junto às comunidades do interior e entorno do Parque Nacional, no combate à queima de áreas para pastagem de maneira indiscriminada.

\section{CONCLUSÕES}

A base da economia das comunidades tradicionais está pautada na agricultura de subsistência ou agricultura familiar, de acordo com o programa instituído pelo governo federal, o qual tem como finalidade oferecer subsídios financeiros e técnicos ao pequeno produtor rural para a criação de animais, que servem para consumo próprio ou para comercialização; a prática do extrativismo; a caça e a pesca para sobrevivência de seu grupo familiar.

A maioria dos domicílios visitados é formada por pequenos agricultores que produzem principalmente, arroz, feijão, milho e mandioca como principais culturas para consumo próprio. Outra atividade bastante enfatizada pelos comunitários foi a criação de animais, com destaque para a galinha, por ser um animal que requer pouco custo, além de ser um alimento com grande valor nutricional, tornando-se um prato bastante consumido pelas comunidades e turistas que visitam o local.

Quanto à criação de gado, atividade que há anos trazem prejuízos ecológicos para região, embora se tenham técnicas de manejo, como o uso controlado do fogo para pastagem, ainda não é o suficiente para não causar impactos negativos à Unidade de Conservação, pois há uma grande discussão acerca da forma de criação de gado no País e como fazer para reduzir tais impactos.

A presença das comunidades provoca conflitos de opiniões devido a perturbações que este ambiente sofre com a presença humana, que utiliza seus recursos naturais de acordo com a finalidade de sua criação, que é para uso indireto, principalmente com algumas atividades praticadas pelos donos de propriedades.

O grande gargalo da política de criação de áreas de conservação é a sua implantação, que ocorre em lugares onde se tem a presença de pessoas, principalmente as da categoria de Proteção Integral. É preciso uma reflexão sobre tais políticas e a conciliação com a forma sustentável de manter estes grupos humanos nos ambientes que escolheram para viver e onde estabeleceram um vínculo com a natureza que os cerca.

AGRADECIMENTOS: Aos moradores das comunidades tradicionais situadas no interior e entorno do Parque 
Nacional da Chapada das Mesas, que contribuíram com as informações, aos funcionários do ICMBio, que ofereceram apoio logístico para realização da pesquisa e ao Laboratório de Biologia Vegetal do CESC/UEMA que colaboraram na tabulação dos dados. Ao Programa de Pós-Graduação em Biodiversidade, Ambiente e Saúde/PPGBAS, pela oportunidade para o desenvolvimento desta pesquisa.

\section{REFERÊNCIAS}

ARAÚJO, M. L. M. N.; REINALDO, L. R. L. R.; SOUSA, J. S.; ALMEIDA, P. G.; ALVES, L. S.; WANDERLEY, J. A. C.. Impactos ambientais nas margens do Rio Piancó causados pela agropecuária. Revista Brasileira de Gestão Ambiental, v.4, n.1, p.13-33, 2010

BRASIL. Lei no 9.605, de 12 de fevereiro de 1998. Lei de crimes ambientais, e dá outras providências. Brasília: DOU, 1998.

BRASIL. Lei no 9.985, de 18 de julho de 2000. Regulamenta o art. 225, § 1o, incisos I, II, III e VII da Constituição Federal. Institui o Sistema Nacional de Unidades de Conservação da Natureza e dá outras providências, e dá outras providências. Brasília: DOU, 2000.

BRASIL. Decreto no 6.040 de 7 de fevereiro de 2007. Institui a Política Nacional de Desenvolvimento Sustentável dos Povos e Comunidades Tradicionais, e dá outras providências. Brasília: DOU, 2007.

BARRETO FILHO, H. T. F.. Populações tradicionais: introdução à crítica da ecologia política de uma noção. In: ADAMS, C.; MURRIETA, R.; NEVES, W.. Sociedades caboclas amazônicas: modernidade e invisibilidade. São Paulo: Annablume, 2006. p.109-143.

BRUNO, N. L.; PROFICE, C. C.; AGUIAR, P. C. B.; FERRAZ, M. I. F.. Apego ao lugar e sustentabilidade ambiental em uma comunidade rural do sul do estado da Bahia, Brasil. Revista Gestão \& Sustentabilidade Ambiental, v.7, n.1, p.206-234, 2018. DOI: http://dx.doi.org/10.19177/rgsa.v7e12018206$\underline{234}$

COSTA, R. A.. A identidade e o conhecimento etnobotânico dos moradores da Floresta Nacional do Amapá. Dissertação (Mestrado em Biodiversidade Tropical) - Universidade Federal do Amapá, Macapá, 2013.

CARVALHO, J. S. B.; MARTINS, J. D. L. M.; MENDONÇA, M. C. S.; LIMA, L. D.. Uso popular das plantas medicinais na comunidade da várzea, Garanhuns-PE. Revista de Biologia e Ciências da Terra, Campina Grande, v.13, n.2, p.58-65, 2013.

CAMPOS, A. A.; BATISTA, R. D. C.; SANTOS, C. A.; SOUSA, M. F. L.. Educação e percepção ambiental na área do Parque Nacional Serra da Capivara-PI. Revista Internacional de Direito Ambiental e Políticas Públicas, Macapá, n.8, p.107120, 2016.

DOI: http://dx.doi.org/10.18468/planetaamazonia.2016n8.p $\underline{107-120}$

CASTILHO, M. A.; ARENHARDT, M. M.; LE BOURLEGAT, C. A.. Cultura e identidade: os desafios para o desenvolvimento local no assentamento Aroeira, Chapadão do Sul, MS. Interações, Campo Grande, v.10, n.2, p.159-169, 2009. DOI: http://dx.doi.org/10.1590/S1518-70122009000200004
COLLINS, P. H.. The New Politics of Community. American Sociological Association, v.75, n.1, p.7-30, 2010. DOI: http://doi.org/10.1177/0003122410363293

DIEGUES, A. C.. O mito moderno da natureza intocada. 3 ed. São Paulo: Hucitec, 1996.

FIGUEIREDO, L. V. R.. Percepção ambiental em unidade de conservação de proteção integral. Dissertação (Mestrado em Desenvolvimento Social) - Universidade Estadual de Montes Claros, Belo Horizonte, 2011.

FERREIRA, M. D. P.; COELHO, A. B.. Desmatamento recente nos Estados da Amazônia Legal: uma análise da contribuição dos preços agrícolas e das políticas governamentais. Revista Economia Sociologia Rural, v.53, n.1, p.91-108, 2015. DOI: http://dx.doi.org/10.1590/1234-56781806-9479005301005

GIL, A. C.. Metodologia do ensino superior. 4 ed. São Paulo: Atlas, 2011.

GODARD, O.; HENRY, C. LAGADEC, P.; MICHEL-KERJAN, E.. Traité des Nouveaux Risques. Précaution, crise, assurance. Gallimard, 2002

GUANAES, S. A.. ‘Meu Quintal não é Parque!' Populações Locais e Gestão Ambiental no Parque Nacional da Chapada Diamantina-BA. Tese (Doutorado em Ciências Sociais) Universidade Estadual de Campinas, São Paulo, 2006.

HENRY-SILVA, G. G.. A importância das unidades de conservação na preservação da diversidade biológica. Revista LOGOS, n.12, p.127-151, 2005.

ICMBIO; MMA. Ministério do Meio Ambiente. Nota Técnica no 001/2016. Carolina/MA, jan. de 2016. Brasília, 2016a.

ICMBIO; MMA. Ministério do Meio Ambiente. Mapa Temático e Dados Geoestatísticos das Unidades de Conservação Federal. Brasília, 2016b.

LAGO, A. A. C.. Estocolmo, Rio e Johanesburgo: O Brasil e as três conferências ambientais das Nações Unidas. Brasília: Thesaurus, 2006.

LAKATOS, E. M.; MARCONI, M. A.. Metodologia científica. 6 ed. São Paulo: Atlas, 2011.

MARQUES, A. R.. Saberes geográficos integrados aos estudos territoriais sob a ótica da implantação do Parque Nacional da Chapa das Mesas, sertão de Carolina. Tese (Doutorado em Geografia) - Universidade Estadual Paulista, São Paulo, 2012.

MATTAR, F. N.. Pesquisa em marketing. 4 ed. São Paulo: Atlas, 2007. 
MOTA, D. M.; PEREIRA, E. O.. Extrativismo em Sergipe: a vulnerabilidade de um modo de vida?. Raízes, Campina Grande, v.27, n.1, p.71-79, 2009.

MMA. Ministério do Meio Ambiente. Centro Nacional de Prevenção e Combate aos Incêndios Florestais - PREVFOGO. Parque Nacional da Chapada das Mesas. Plano operativo de prevenção e combate aos incêndios florestais do Parque Nacional da Chapada das Mesas. Brasília: MMA, 2007.

OLAIDE, A. R.; DIAS, B. O.. Agricultura orgânica e agroecologia na Bahia: atores experiências. In: UZÊDA, M. C. O.. Desafio da agricultura sustentável: alternativas viáveis para o sul da Bahia. Ilhéus: Editus, 2004. p.71-96.

PINTO, E. P. P.; AMOROZO, M. C. M.; FURLAN, A.. Conhecimento popular sobre plantas medicinais em comunidades rurais de Mata Atlântica - Itacaré, BA, Brasil. Acta Botânica Brasileira, v.20, n.4, p.751-762, 2006.

SILVA, M. L. A.; ARAÚJO, M. F. V.; CONCEIÇÃO, G. M.. Identidade e modo de vida dos moradores do Parque Nacional da Chapada das Mesas, Maranhão, Brasil. Biota Amazônia, v.7, n.4, p.41-47, 2017. DOI: http://dx.doi.org/10.18561/21795746/biotaamazonia.v7n4p41-47
SILVA, M. L. A.; ARAÚJO, M. F. V.; CONCEIÇÃO, G. M. Percepção dos atores sociais sobre os benefícios socioambientais com a implantação do Parque Nacional da Chapada das Mesas (MA). Revista Brasileira de Educação Ambiental, v.13, n.2, p.32-52, 2018.

DOI: https://doi.org/10.34024/revbea.2018.v13.2572

SILVA, M. L. A.; ARAÚJO, M. F. V.; CONCEIÇÃO, G. M.. Percepção ambiental dos moradores do Parque Nacional da Chapada das Mesas, no domínio fitogeográfico do Cerrado Brasileiro. Revista Espcaios, v.38, n.22, p.33-50, 2016.

SHIRAISHI, J. C.. Percepção Ambiental sobre a Reserva Biológica da Contagem, DF: Uma Análise Preliminar. In: ENCONTRO NACIONAL DA ANAPPAS, 5. Anais. Florianópolis, 2010.

TOLEDO, V. M.; BARRERA-BASSOLS, N.. A etnoecologia: uma ciência pós-normal que estuda as sabedorias tradicionais. Revista Desenvolvimento e Meio Ambiente, n.20, p.31-45, 2009. DOI: http://dx.doi.org/10.5380/dma.v20i0.14519

WÜST, C.; TAGLIANI, N.; CONCATO, A. C.. A pecuária e sua influência impactante ao meio ambiente. In: CONGRESSO BRASILEIRO DE GESTÃO AMBIENTAL, 6. Anais. Porto Alegre, 2015.

A CBPC - Companhia Brasileira de Produção Científica (CNPJ: 11.221.422/0001-03) detém os direitos materiais desta publicação. Os direitos referem-se à publicação do trabalho em qualquer parte do mundo, incluindo os direitos às renovações, expansões e disseminações da contribuição, bem como outros direitos subsidiários. Todos os trabalhos publicados eletronicamente poderão posteriormente ser publicados em coletâneas impressas sob coordenação da Sustenere Publishing, da Companhia Brasileira de Produção Científica e seus parceiros autorizados. Os (as) autores (as) preservam os direitos autorais, mas não têm permissão para a publicação da contribuição em outro meio, impresso ou digital, em português ou em tradução. 